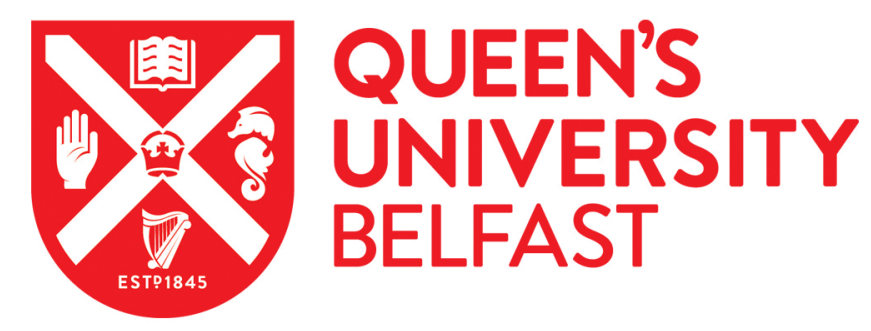

\title{
Performance comparison of a two PV module experimental setup using a modified MPPT algorithm under real outdoor conditions
}

Soulatiantork, P. (2018). Performance comparison of a two PV module experimental setup using a modified MPPT algorithm under real outdoor conditions. Solar Energy, 169, 401-410. [SE6801].

https://doi.org/10.1016/j.solener.2018.04.065

Published in:

Solar Energy

Document Version:

Peer reviewed version

Queen's University Belfast - Research Portal:

Link to publication record in Queen's University Belfast Research Portal

Publisher rights

(c) 2018 Elsevier Ltd. All rights reserved.

This manuscript version is made available under the CC-BY-NC-ND 4.0 license http://creativecommons.org/licenses/by-nc-nd/4.0/,which permits distribution and reproduction for noncommercial purposes, provided the author and source are cited.

\section{General rights}

Copyright for the publications made accessible via the Queen's University Belfast Research Portal is retained by the author(s) and / or other copyright owners and it is a condition of accessing these publications that users recognise and abide by the legal requirements associated with these rights.

Take down policy

The Research Portal is Queen's institutional repository that provides access to Queen's research output. Every effort has been made to ensure that content in the Research Portal does not infringe any person's rights, or applicable UK laws. If you discover content in the Research Portal that you believe breaches copyright or violates any law, please contact openaccess@qub.ac.uk. 


\title{
Performance comparison of a two PV module experimental setup using a modified MPPT algorithm under real outdoor conditions
}

\author{
P. Soulatiantork \\ Dipartimento di Elettronica, Informazione e Bioingegneria, Politecnico di Milano, 20133 Milan, Italy \\ (e-mail: payam.soulatiantork@polimi.it)
}

\begin{abstract}
The importance of Photovoltaic (PV) systems as a sustainable energy resource is widely recognized. The real maximum power point (MPP) is the most crucial parameter that must be considered to assure that maximum power is harvested from the PV module at all operating points. To this end, several PV testing systems and MPP tracker algorithms have been developed to find the real MPP. Issues related to the comparison of maximum power point tracking (MPPT) algorithms, evaluation, and comparison of PV testing system performances are the repeatability and reproducibility of testing conditions such as solar irradiation and PV module temperature.

In this work, a flexible, low-cost testing system for PV applications is presented, and two identical PV modules have been compared at the same environmental conditions. A model-based (MB) MPPT algorithm, previously developed by the authors of this study, has been used. The MB algorithm has been evaluated and its efficiency is reported as 99.65\%. The experimental test has been carried out and the performance of the developed architecture is validated, and two PV modules have been compared in real-time. It has been shown that the generated energy percentage difference between two identical PV modules is $0.6 \%$. It is also worth mentioning that the proposed testing system is capable of hosting, evaluating and comparing four different MPPT algorithms, four PV modules and a combination of them.
\end{abstract}

Index Terms - Photovoltaic modules, MPPT algorithms, DC-DC Converter, Real-time measurement

\section{INTRODUCTION}

$\mathrm{P}$ $\mathrm{V}$ energy is considered one of the most important sustainable energies amongst all renewable technologies. In order to extract the most useful energy out of the PV module, the real peak power of the PV module must be identified in real-time. To this end, several MPPT algorithms have been developed. To evaluate and compare the algorithms and PV modules performances, a dedicated photovoltaic testing system must be developed. Repeatability and reproducibility are two crucial parameters in the evaluation and comparison of MPPT algorithms and PV modules. Specifically, the experimental comparison of the performance of the PV modules is challenging due to the difficulty in reproducing environmental conditions. This is because the power generated by the PV modules is highly dependent on the cell temperature and solar irradiation. The use of artificial light sources to tackle the problem of reproducing the solar irradiation is not practical due to the cost and physical space required to use them [1].

Consequently, an experimental testing system for PV application is required, allowing the comparison between PV modules and MPPT algorithms. In general, a PV system is divided into PV modules and a balance of system (BoS), which comprises all the non-module components of PV plants. From the reliability point of view, deep root failure causes of PV module and BoS are thoroughly studied to enhance the maintenance activities. A Markovian Model is built up, considering all the possible failure modes, in order to assess the probability of each failure mode occurrence and estimate the mean time to failure, probability density function of the time to module failure, hazard and survival functions of PV module and BoS [2][3].

Not only the reliability analysis is important for PV modules but also it would be interesting to see if two or more identical PV modules of the same brand can produce the same energy at the same environmental conditions. This can be done by using the same MPPT algorithm and the same controller and comparing the energy produced by each PV module. MPPT algorithm and the type of the controller play important roles to compare the identical PV module performances. To increase the efficiency of the PV testing systems, a few MPPT algorithms have been developed to assure delivering the maximum possible power in all operating points [4] [5] [6]. Different types of controllers, such as PI [7], neuro-fuzzy [8] and fuzzy [9], are also used to improve the performance of the PV testing system.

There are several studies where different types of PV modules have been studied in different countries. Three different photovoltaic technologies, which are silicon ( $\mathrm{Si}$ ), polycrystalline silicon ( $\mathrm{pc}-\mathrm{Si}$ ) and monocrystalline silicon (mc-si), have been analyzed and compared in Mohammedia, Morocco, aiming to determine the optimal PV technology [10]. From the generated energy point of view, the authors concluded that at low temperature and irradiation levels, polycrystalline modules could produce more energy in comparison with the monocrystalline modules. It is the other way round for the high temperature and solar irradiation level. Another research carried out in Perth, Australia, in which five different types of PV modules have been 
compared. The monthly and annual performance ratios (PRs) have been calculated and compared in a study [11]. Using individual MPPT algorithms for each module, it has been concluded that the thin film modules would generate the most energy at that site. An $8.88 \mathrm{~kW}$ grid-connected PV system installed in Singapore examined the status of solar technologies through a case study consisting of three different technologies of PVs such as monocrystalline, polycrystalline, and thin film. The conversion efficiencies are reported as $8.12 \%, 7.45 \%$ and $6.75 \%$ for monocrystalline, polycrystalline, and thin film, respectively [12].

In another approach of comparing different PV modules, the authors presented a comparison between a single and two diode models of the PV module conducted in Matlab software. They showed that both models have the same ability to find the model parameters; however, single diode model has less computation time, and two diode model is more accurate in different power ranges [13]. A thorough numerical comparative analysis study of several different single diode models of PV modules is carried out and the relative errors between each model output and the experimentally validated data are computed at three indicative points, open circuit voltage $\left(\mathrm{V}_{\mathrm{oc}}\right)$, short circuit current $\left(\mathrm{I}_{\mathrm{sc}}\right)$ and maximum power point. The results determined the most accurate model for single diode PV modules [14].

Previous studies were more focused on comparing different PV technologies and characterizing them under different environmental conditions [15]; however, identical PV modules at the same environmental conditions have not been compared yet. Just a few simulations-based works compare different MPPT algorithms at the same environmental conditions, without experimental evaluation [16] [17].

Therefore, in this work, an experimental system for testing PV modules featuring low cost, flexibility, the capability of characterizing PV modules and implementing MPPT algorithms in real-time is presented. This setup resolves the issue of reproducibility and repeatability of the environmental conditions.

Fig. 1 shows the architecture of the testing system proposed and used in this work. The architecture consists of the main board, which allows the real-time measurement and control. The solar irradiation and temperature have also been measured, which are useful in implementing the MB algorithms.



Fig. 1. Block diagram of the proposed testing system.

As depicted in Fig. 1, the current and the voltage of each PV module are measured by the data acquisition card and sent to the control system. MPPT algorithms are embedded in the control system, and each module MPP can be tracked independently by manipulating the duty cycle of the related DC-DC power converter. Identical power converters have been employed to make the comparison fair.

The paper is organized as follows. Section II explains the different structures and designs of PV testing systems. The hardware platform used in this paper is described completely in Section III for two identical PV modules comparison. Section IV is dedicated to MB algorithm employed in the paper. Section $\mathrm{V}$ is discussing the characterization and comparison of two identical $\mathrm{PV}$ modules in real-time and Section VI presents the main conclusions.

\section{Photovoltaic Testing Systems}

In the literature, several PV testing systems can be found. Evaluating the characteristic curves of PV modules using variable 
resistors is considered a low-cost PV testing system method. This method is usually used in low power applications as finding resistors for higher power rating systems is difficult.

Fig. 2 shows the schematic of a variable resistor technique as a PV testing system, which can characterize seven PV modules at the same time [18].

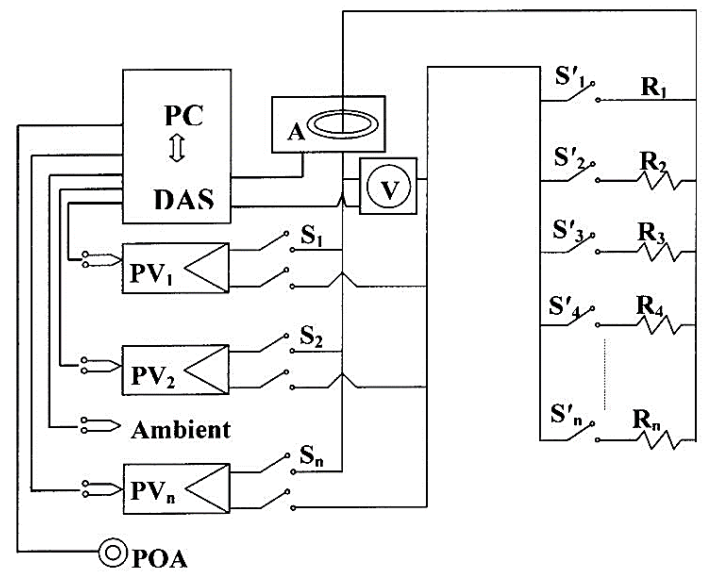

Fig. 2. Schematic of a variable resistor technique [18].

An array of resistors is employed as a load to PV module, which allows sweeping from $\mathrm{V}_{\mathrm{oc}}$ to $\mathrm{I}_{\mathrm{sc}}$. The issue related to this technique is that the system is slow, which makes it difficult to characterize the PV modules in the fast-changing environmental conditions.

As depicted in Fig. 3, capacitors can be used as a load to the PV module connected through insulated gate bipolar transistors (IGBTs). The $\mathrm{I}_{\mathrm{sc}}$ and the $\mathrm{V}_{\mathrm{oc}}$ are $80 \mathrm{~A}$ and $800 \mathrm{~V}$, respectively. This system allows sweeping the whole I-V curve of the PV module. In order to have reliable results, the capacitors must have a very high quality [19]. Furthermore, for higher voltage and higher power applications, the size of the capacitors should be increased, which is a disadvantage of this method. Another demerit of this system is that the capacitors must be fully discharged to perform a new test.

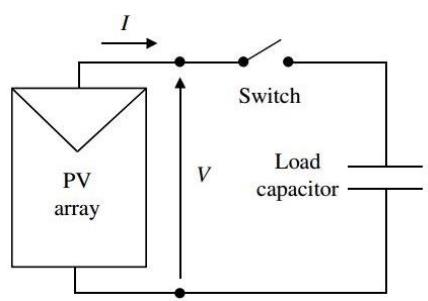

Fig. 3. Capacitive load method with a switch [19].

Fig. 4 depicts the principle scheme of the electronic load method, which employs transistors as a load of PV module. Sweeping from the $\mathrm{V}_{\mathrm{oc}}$ to the $\mathrm{I}_{\mathrm{sc}}$ can be carried out by changing the duty cycle applied to the gate of the switches from 0 to 1 .

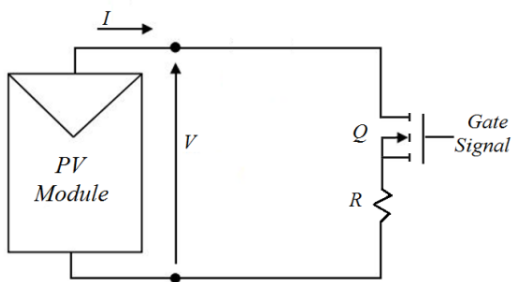

Fig. 4. Electronic load method.

As an example of a cost-effective electronic load system, a system is developed and presented in a study [20]. As it is depicted in Fig. 5, a number of BJTs act as a load of the PV module to sweep the whole characteristics curve. It allows the system to characterize different sizes of PV modules at less cost. The only disadvantage of this method is that the switches must dissipate the power, thus limiting the power of the testable PV module. 


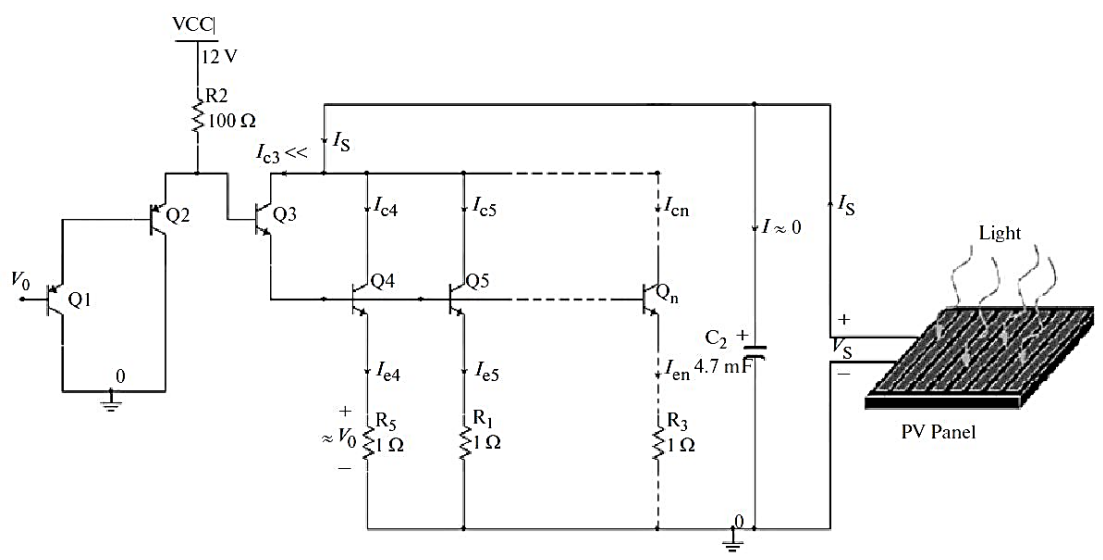

Fig. 5. Cascaded power transistors for high power rated PV modules [20].

Another example of electronic load method is presented in a study [21] and depicted in Fig. 6, where the authors employed a metal-oxide-semiconductor field-effect (MOSFET) transistor as the switch. The system has the capability of characterizing I-V and P-V curves and measuring the $\mathrm{I}_{\mathrm{sc}}$ and the $\mathrm{V}_{\mathrm{oc}}$ using peak detectors. The voltage at MPP $\left(\mathrm{V}_{\mathrm{mp}}\right)$ and current at MPP $\left(\mathrm{I}_{\mathrm{mp}}\right)$ are also measured in this architecture. To handle higher power applications, several MOSFETs can be employed in parallel.

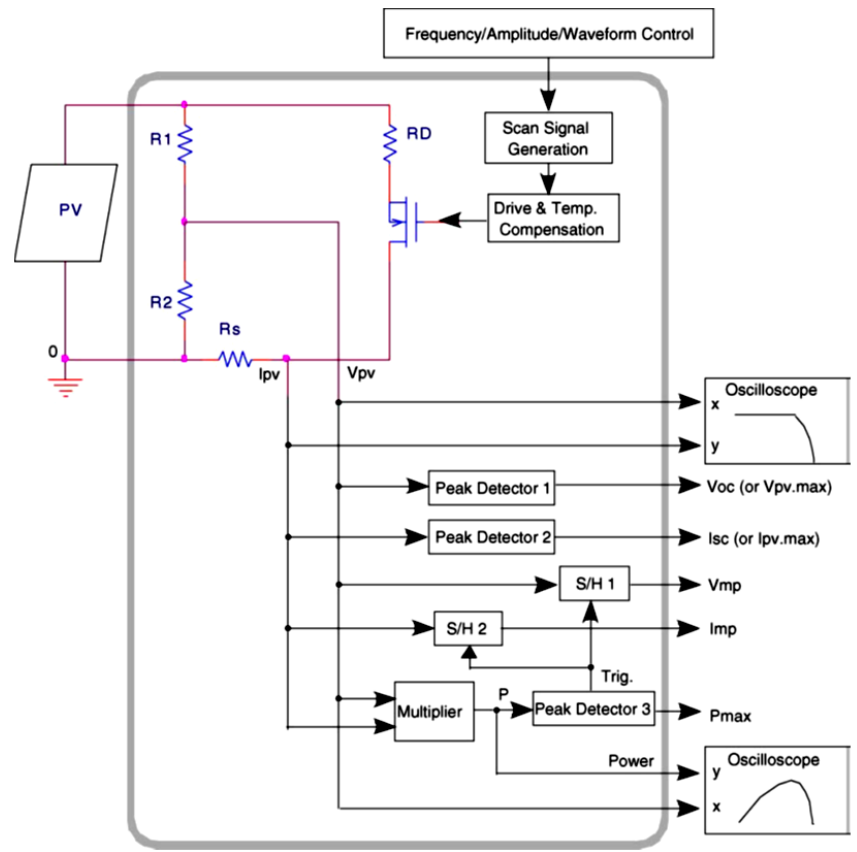

Fig. 6. Block diagram of PV testing system [21].

DC-DC converters are very fast response devices that allow testing the PV systems and can easily act as a variable resistor similar to the electronic load method. As shown in Fig. 7, the duty cycle must be changed between 0 and 1 to sweep the I-V characteristic curve of the PV module.

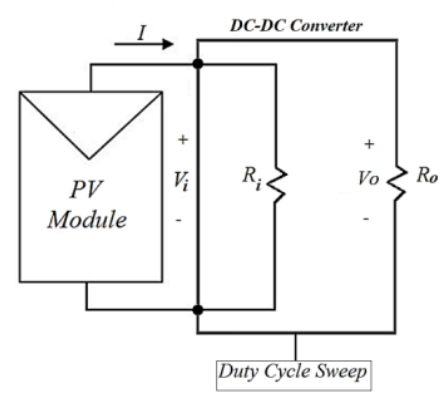

Fig. 7. DC-DC converter scheme for PV testing system. 
Current ripple due to the switching of DC-DC converters is one of the disadvantages of this technique. However, this ripple can be reduced using coupled inductors and interleaved DC-DC converters. Different methods for reducing the current ripple are also can be found in the literature [22][23].

In literature, several DC-DC converters topologies have been employed. It is shown that to have a complete sweep of the curves including the $I_{s c}$ and the $V_{o c}$, buck or boost topologies are not suitable, and a combination of them must be applied. In fact, buck converter cannot force the short circuit state while boost converter cannot impose the $\mathrm{V}_{\mathrm{oc}}$. Therefore, a buck-boost converter topology is necessary for this application [24].

Zeta, single-ended primary-inductor converter (SEPIC), Buck-Boost and Cuk converters are classical examples of buck-boost converters. For PV applications, the most crucial parameters are current ripple and noise, which can affect the measurement accuracy. Therefore, amongst these topologies, buck-boost and Zeta are not suitable for this application because the switch is in series with the PV module, which causes a current ripple in the system. SEPIC and Cuk converters need just one switch, which increases the reliability of the system. For the abovementioned reasons, SEPIC topology has been chosen in this work.

\section{THE TESTING SYSTEM}

To integrate the real-time measurement and control and to characterize PV modules and compare them at the same environmental condition, the hardware platform has been developed and is presented in this section. The developed system measures the current, voltage, solar irradiation and module temperature.

The control system is based on PC and Simulink/Matlab environment, which gives the opportunity to characterize the PV module and implement the MPPT algorithms in real-time. The ControlDesk software by dSPACE has been used as a graphical interface.

A dSPACE system provides the capability to develop user-friendly control modules for online monitoring and supervision. In this paper, tests have been done in Simulink/ Matlab environment with the SimPower/ Matlab toolbox and dSPACE real-time interface (RTI1104) block set libraries. The connection diagram of dSPACE used in this paper is depicted in Fig. 8. The PC has access to the data measured by the DAQ card and sends the control command to the DC-DC power converter.



Fig. 8. Diagram of dSPACE controller board and the connections.

The control scheme used for each power converter is depicted in Fig. 9. The control system, which is the MPPT algorithm implemented in Matlab software, sends a signal to the pulse width modulator (PWM). PWM output signal then controls the power converter through a gate driver circuit. A Proportional Integral (PI) control strategy has been used as a controller in this paper [25] [26]. 


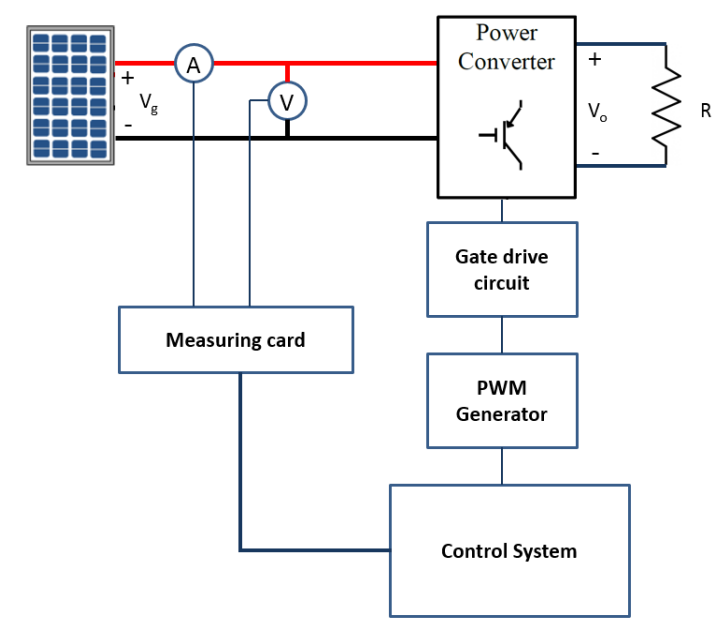

Fig. 9. Power converter control scheme.

PV module temperature and solar irradiation have been measured via PT100 temperature sensor and a Pyranometer, respectively. ADAM 4000, which is an intelligent interface for environmental sensors, has been employed to acquire the signal of temperature and irradiation and sends them to dSPACE board via RS-232 and RS-485 communication protocols [27]. Fig. 10 shows the SEPIC converter, which allows setting the working point of the PV module. The constraints on designing the power converter are the power up to $200 \mathrm{~W}$, voltage up to $100 \mathrm{~V}$ and current up to $6 \mathrm{~A}$. The lifetime-enhancement analysis of the converter is also presented and discussed in a study [28].

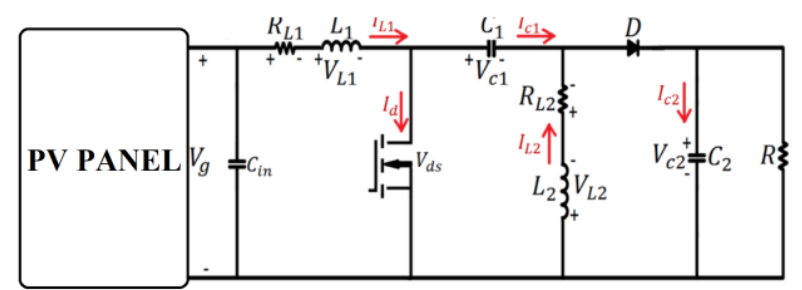

Fig. 10. SEPIC converter topology.

For the present work, two identical $80 \mathrm{~W}$ solar modules installed on the roof of DEIB department at Politecnico di Milano have been considered and compared. PV module parameters are summarized in TABLE I. As reported in the table, the $\mathrm{V}_{\text {oc }}$ and the $\mathrm{I}_{\mathrm{sc}}$ are $21.33 \mathrm{~V}$ and $5.03 \mathrm{~A}$, respectively.

Table I. $80 \mathrm{~W}$ PV module parameters.

\begin{tabular}{c|c|c}
\hline PV Parameters & Description & Value \\
\hline $\mathbf{V}_{\text {oc }}$ & Open circuit Voltage & $\mathbf{2 1 . 3 3 ~ V}$ \\
\hline $\mathbf{I}_{\mathbf{s c}}$ & Short circuit current & $\mathbf{5 . 0 3} \mathbf{~ A}$ \\
\hline $\mathbf{P}_{\max }$ & Maximum power at STC & $\mathbf{8 0 ~ W}$ \\
\hline Tolerance & -- & $\mathbf{0} /+\mathbf{5 W}$ \\
\hline
\end{tabular}

Fig. 11 depicts the PCB board accommodating the SEPIC topology and the current and voltage sensors. According to Fig. 11, I/O socket is mounted to send and receive the power and control signals. On the converter, there are two measurement sections to measure the input and output voltages and currents, thus allowing the converter efficiency calculations [29] [30]. The measured parameters have also been used to calculate the PV module power and thus the energy. 

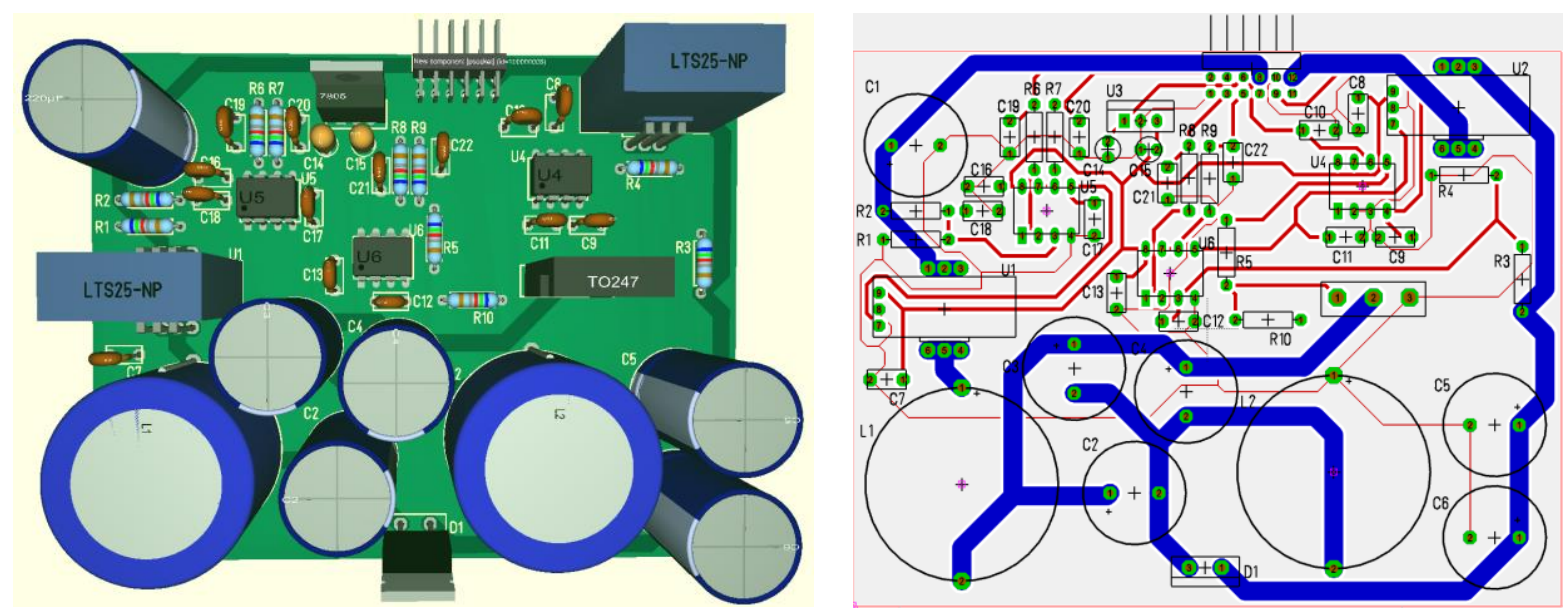

Fig. 11. Power converted PCB board; Front Side (Left), Backside (Right).

As can be seen in Fig. 12, to measure the voltage provided by the PV module, two resistors (R1 and R2) are used in parallel with the PV module as a voltage divider. The voltage across $\mathrm{R} 2\left(\mathrm{~V}_{\mathrm{R} 2}\right)$ is filtered using a low pass filter and then acquired by the dSPACE rti1104 analog to digital converter (ADC) board.

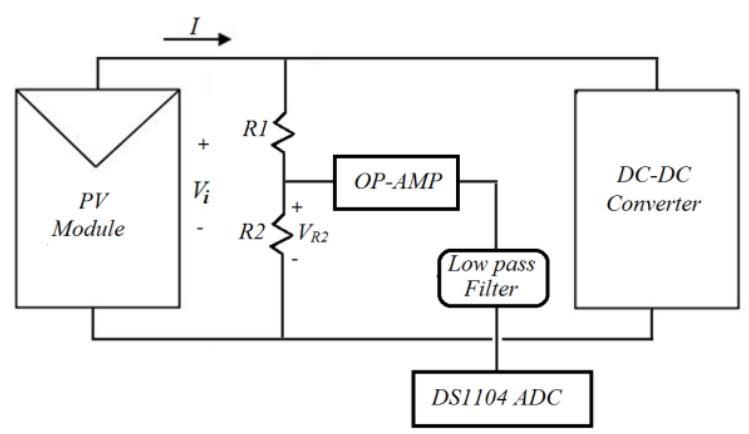

Fig. 12. Input and output voltage measurement technique.

As shown in Fig. 13, the current provided by the PV module is measured through a LEM LTS-6NP current sensor. The sensed current is measured by the ADC card through a low pass filter.

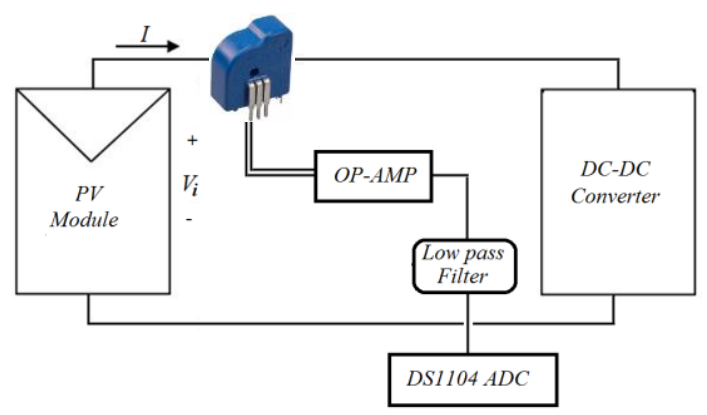

Fig. 13. Input and output current measurement technique.

\section{MODEL-BASED MPPT ALGORITHM}

To achieve the highest PV system efficiency, the MPPT algorithms must provide a very accurate MPP at the reference of the control system as shown in Fig. 9. This reference can be either the $V_{m p}$ or the $I_{m p}$. In comparison with the conventional MPPT algorithms such as perturb and observe ( $\mathrm{P} \& \mathrm{O})$ and incremental conductance (IC) MPPT algorithms, MB algorithms are more efficient in sudden environmental changes as they offer a better dynamic response. The MB MPPTs are designed to estimate the value of $\mathrm{V}_{\mathrm{mp}}$ or $\mathrm{I}_{\mathrm{mp}}$ by means of a PV model. Many expressions of the $\mathrm{V}_{\mathrm{mp}}$ are reported in the different literature, and the following equation represents an accurate, simple expression of $\mathrm{V}_{\mathrm{mp}}$ and $\mathrm{I}_{\mathrm{mp}}$, [30] 


$$
\begin{gathered}
V_{m p}=V_{m p 0}\left[1+\beta_{m p}\left(T-T_{0}\right)+\delta_{1} \ln \left(\frac{G}{G_{0}}\right)+\delta_{2} \ln ^{2}\left(\frac{G}{G_{0}}\right)\right] \\
I_{m p}=I_{m p 0} \frac{G}{G_{0}}\left[1+\alpha_{m p}\left(T-T_{0}\right)\right]
\end{gathered}
$$

where $\mathrm{V}_{\mathrm{mp} 0}$ and $\mathrm{I}_{\mathrm{mp} 0}$ are the MPP voltage and current corresponding to the standard conditions with the temperature at $\mathrm{T}_{0}[\mathrm{~K}$ ] and solar irradiation at $\mathrm{G}_{0}\left[\mathrm{~W} / \mathrm{m}^{2}\right]$. $\mathrm{T}$ is the $\mathrm{PV}$ module temperature in Kelvin, and $\mathrm{G}$ is the solar irradiation intensity in watts per square meter. Then, $\beta_{\mathrm{mp}}, \delta_{1}, \delta_{2}$, and $\alpha_{\mathrm{mp}}$ are the temperatures and solar irradiation correction coefficients of MPP voltage and current [31].

The only issue with MB algorithms is that they usually need the solar irradiation level to calculate the $V_{m p}$ or $I_{m p}$. Solar irradiation then must be measured by means of a Pyranometer, which is very expensive and can increase the cost of the setup.

Recently, the authors of this study have proposed a model that is able to estimate the module incident irradiation without measuring the solar irradiation [32] [33]. $\mathrm{V}_{\mathrm{mp}}$ can be efficiently estimated and the experimental results presented in a study [34] shows that the MPP is estimated with a very high degree of accuracy. If we consider that the temperature dependency of the $\mathrm{I}_{\mathrm{mp}}$ is negligible, it can be concluded that

$$
\frac{I_{m p}}{I_{m p 0}} \cong \frac{G}{G_{0}}
$$

It's reasonable to conclude that the $\mathrm{I}_{\mathrm{mp}}$ is directly proportional to the solar irradiation $\mathrm{G}$ [33]. Therefore, $\mathrm{G}$ can be replaced by $\mathrm{I}_{\mathrm{mp}}$, and Eq. 1 can be presented as the following equation,

$$
V_{m p} \cong V_{m p 0}\left[1+\beta_{m p}\left(T-T_{0}\right)+\delta_{1} \ln \left(\frac{I_{m p}}{I_{m p 0}}\right)+\delta_{2} \ln ^{2}\left(\frac{I_{m p}}{I_{m p 0}}\right)\right]
$$

Eq.4 can easily estimate the $V_{m p}$ utilizing $I_{m p}$. It's clear that $I_{m p}$ is not known until the system is adjusted to operate at the maximum power point, and the $\mathrm{V}_{\mathrm{mp}}$ is highly dependent on the temperature. In addition, a rough approximation of $\mathrm{V}_{\mathrm{mp}}$ is typically obtained even by neglecting the effects of solar irradiation. Therefore, it can be reasonably assumed that after the first application of the formula, the PV voltage is close to $\mathrm{V}_{\mathrm{mp}}$, and at the same time, the measured current should be close to $\mathrm{I}_{\mathrm{mp}}$ [33]. At this point, replacing the MPP current with the measured current, Eq.4 can be rewritten as the following:

$$
V_{m p} \cong V_{m p 0}\left[1+\beta_{m p}\left(T-T_{0}\right)+\delta_{1} \ln \left(\frac{I}{I_{m p 0}}\right)+\delta_{2} \ln ^{2}\left(\frac{I}{I_{m p 0}}\right)\right]
$$

which is the basis of the mentioned MB MPPT technique and can be rewritten as:

$$
V_{m p}=A_{0}+A_{1} T+A_{2} \ln \left(\frac{I}{I_{m p 0}}\right)+A_{3} \ln ^{2}\left(\frac{I}{I_{m p 0}}\right)
$$

Using the Ordinary Least Squares method (linear regression), $\mathrm{A}_{0}$ to $\mathrm{A}_{3}$ can be estimated. The application of the method requires applying Eq. 6 in an iterative way to reach the real MPP. As demonstrated, the algorithm converges in a very fast and accurate way [33].

The MB algorithm has been verified by means of the experimental setup described in the previous section. For this test, a 180 W PV module has been used. Table II summarizes the $180 \mathrm{~W}$ PV module parameters. 2900 characteristic curves of the PV module have been acquired over five days in every 30 seconds and for irradiations larger than $200 \mathrm{~W} / \mathrm{m}^{2}$. Each I-V curve has been processed to find the real MPP. 
Table II. $180 \mathrm{~W}$ PV module parameters used for MB algorithm performance validation.

\begin{tabular}{c|c|c}
\hline PV Parameters & Description & Value \\
\hline $\mathbf{V}_{\text {oc }}$ & Open circuit Voltage & $\mathbf{4 4 . 2} \mathbf{~ V}$ \\
\hline $\mathbf{I}_{\mathbf{s c}}$ & Short circuit current & $\mathbf{5 . 2 4} \mathbf{A}$ \\
\hline $\mathbf{P}_{\mathbf{m a x}}$ & Maximum power at STC & $\mathbf{1 8 0 ~ W}$ \\
\hline
\end{tabular}

Fig. 14 depicts the maximum power of the acquired curves $\left(\mathrm{P}_{\mathrm{mp}}\right)$. The same data has been used to verify the hypothesis of proportionality between the maximum power point current $\left(\mathrm{I}_{\mathrm{mp}}\right)$ and solar irradiation $(\mathrm{G})$ as shown in Fig. 15 .

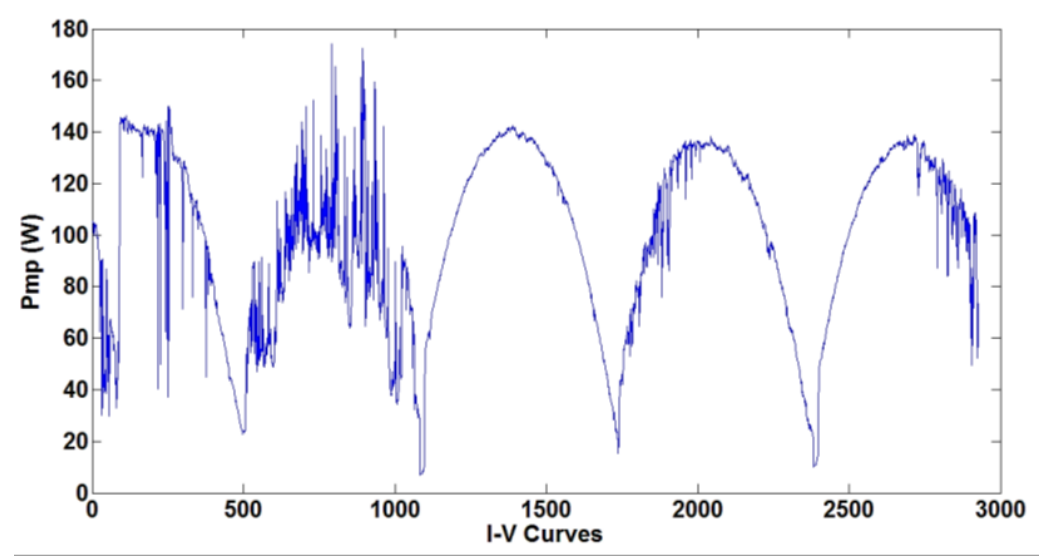

Fig. 14. Power at Maximum Power Point for all characteristic curves $\left(\mathrm{P}_{\mathrm{mp}}\right)$.

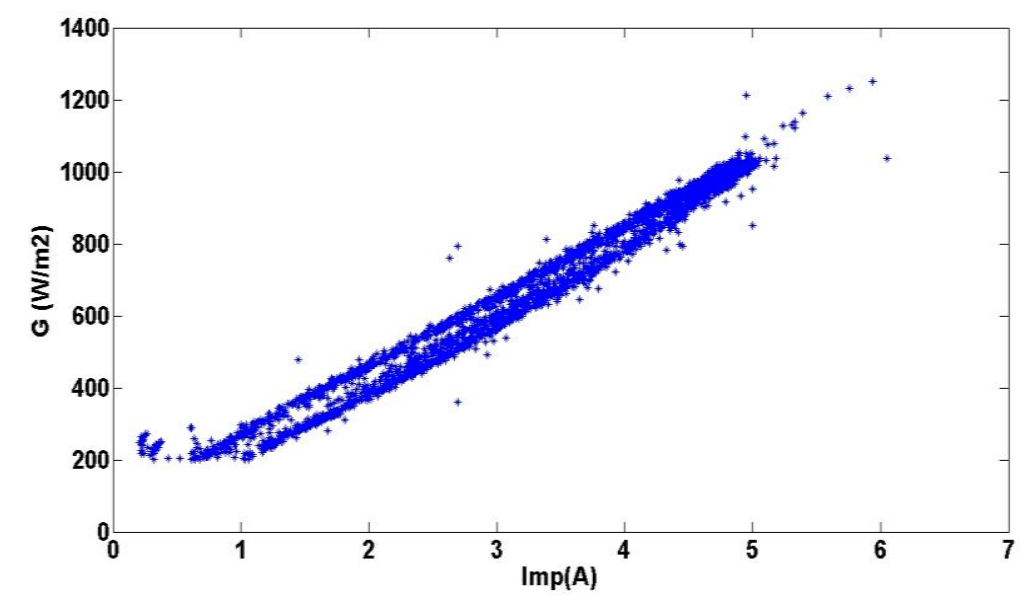

Fig. 15. Solar irradiation (G) vs. $I_{m p}$.

The characteristic curves between 500 and 1750 have been used to extract the parameters of Eq.6 and reported in Table III. The rest of the characteristics curves have been used for model evaluation.

\begin{tabular}{cccc}
\multicolumn{4}{c}{ Table III. MB algorithm parameters. } \\
\hline $\boldsymbol{A}_{\mathbf{0}}$ & $\boldsymbol{A}_{\mathbf{1}}$ & $\boldsymbol{A}_{\mathbf{2}}$ & $\boldsymbol{A}_{\mathbf{3}}$ \\
\hline $74.07 \mathrm{~V}$ & $-0.13 \mathrm{~V} / \mathrm{K}$ & $-0.63 \mathrm{~V}$ & $-1.28 \mathrm{~V}$ \\
\hline
\end{tabular}

The performance of the model has been evaluated by computing the percentage of error in terms of power, which can be written as:

$$
\% \text { Power error }=\frac{P_{m p \_} e^{-P_{m p \_} a}}{P_{m p_{-} a}} * 100
$$

where $\mathrm{P}_{\mathrm{mp} \_}$and $\mathrm{P}_{\mathrm{mp} \_\mathrm{a}}$ are the estimated maximum power by the model and the actual maximum power from the I-V curves, respectively.

As can be seen in Fig. 16, the percentage of MP error is considerably lower than $1 \%$ in high solar irradiation. There are some points with higher errors, which are related to partial shading on the PV modules. 


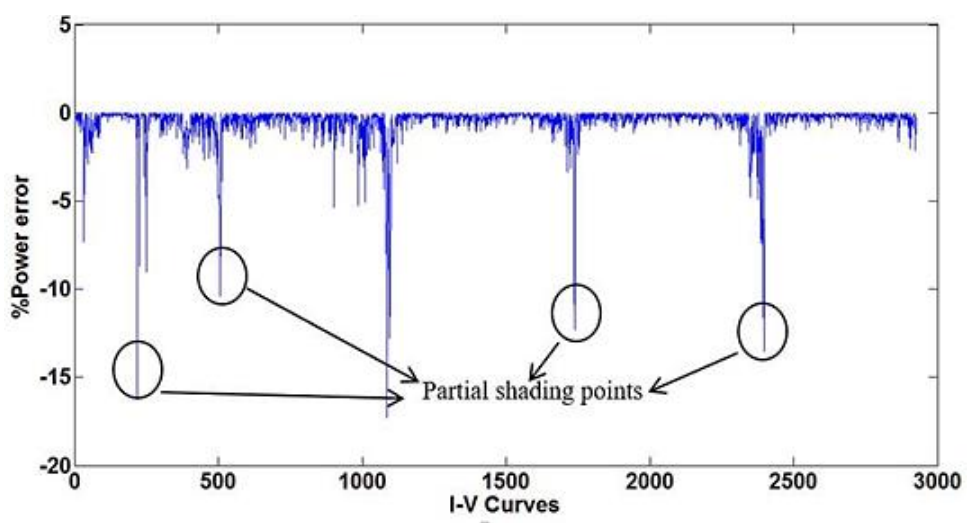

Fig. 16. Percentage power error.

A better evaluation of the algorithm can be done by evaluating the algorithm efficiency in terms of generated energy over a period:

$$
\eta=\left[1-\frac{\left(E_{e}-E_{a}\right)}{E_{a}}\right] * 100
$$

where the $E_{e}$ is the energy estimated by means of the model, and $E_{a}$ is the actual energy calculated from the characteristic curves. We have assumed that the generated power is constant between the acquisition of one curve and the following one. Table IV reports the energy estimated by the model, the actual energy and the efficiency of the model. The model has been evaluated and its efficiency is reported as $99.65 \%$, which demonstrates the excellence of the discussed model.

Table IV. Power utilization efficiency.

\begin{tabular}{c|c|c}
\hline $\boldsymbol{E}_{\boldsymbol{e}}[\mathbf{J}]$ & $\boldsymbol{E}_{\boldsymbol{a}}[\mathbf{J}]$ & $\boldsymbol{\eta}$ \\
\hline 144910 & 145405 & $99.65 \%$ \\
\hline
\end{tabular}

\section{IDENTICAL PV MODULE COMPARISON}

The hardware setup and the MB MPPT algorithm discussed in previous sections have been used to compare the total energy generated by two identical $80 \mathrm{~W}$ PV modules in real-time as presented in the following sections. The same MB MPPT algorithm has been used to track maximum power point of each module, which makes the comparison quite fair.

\section{A. $80 \mathrm{~W}$ MODULES CHARACTERISTICS AND PERFORMANCE COMPARISON USING MB MPPT ALGORITHM}

The MB algorithm discussed in the previous section has been verified by means of the experimental setup described in section II. The experiment consists of a sunny day and a day with variable weather condition. Each I-V curve has been processed to find the real MPP. It must be mentioned that the test has been done for solar irradiations higher than $200 \mathrm{~W} / \mathrm{m}^{2}$, and the characteristic curves were acquired for every 30-second period over one and a half days and approximately 950 characteristic curves were acquired. The solar irradiation and the module temperature are depicted in Fig. 17. As shown in the figure, the irradiation level is in the interval between $200 \mathrm{~W} / \mathrm{m}^{2}$ and $1200 \mathrm{~W} / \mathrm{m}^{2}$. The temperature also varies between $301 \mathrm{~K}$ up to $328 \mathrm{~K}$ for this test.
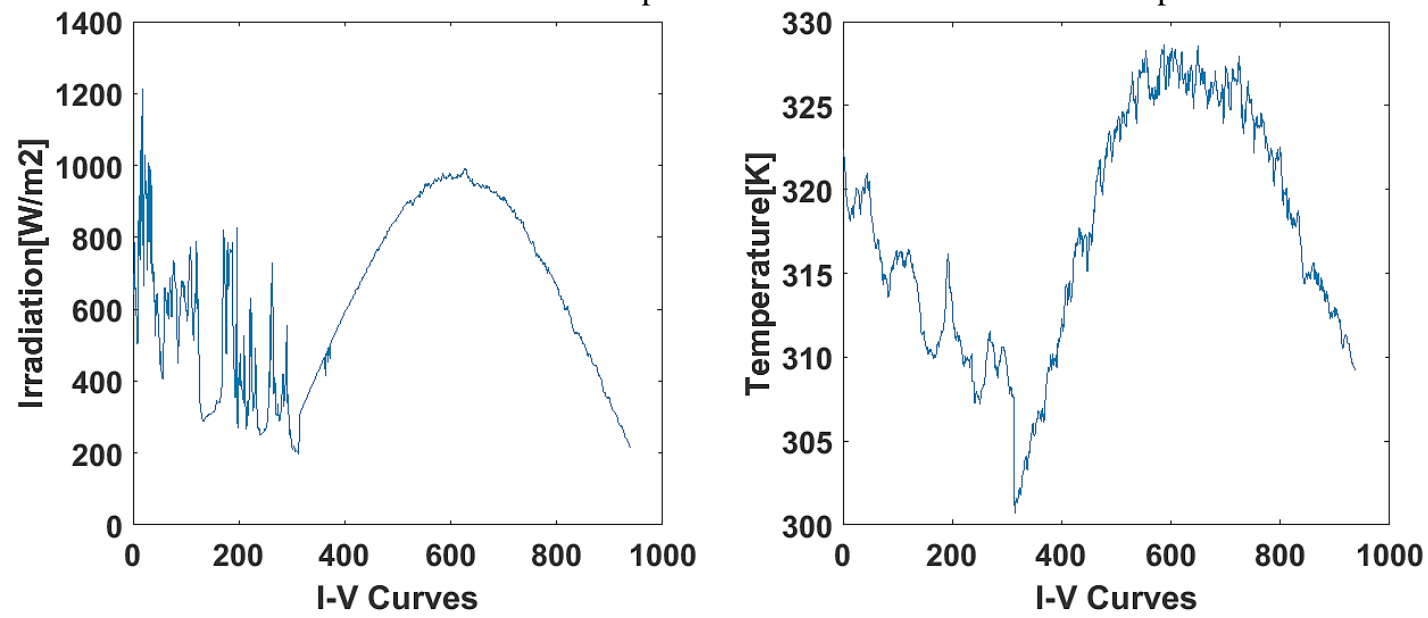

Fig. 17. Solar irradiation and module temperature. 
To have a better explanation of the power produced by each PV module, power, and the power difference are shown on the left and the right side of Fig. 18, respectively. The power produced by PV modules is in the interval between $14 \mathrm{~W}$ and $80 \mathrm{~W}$. The power difference is maximum 4 watts, which occurs in high irradiation levels.
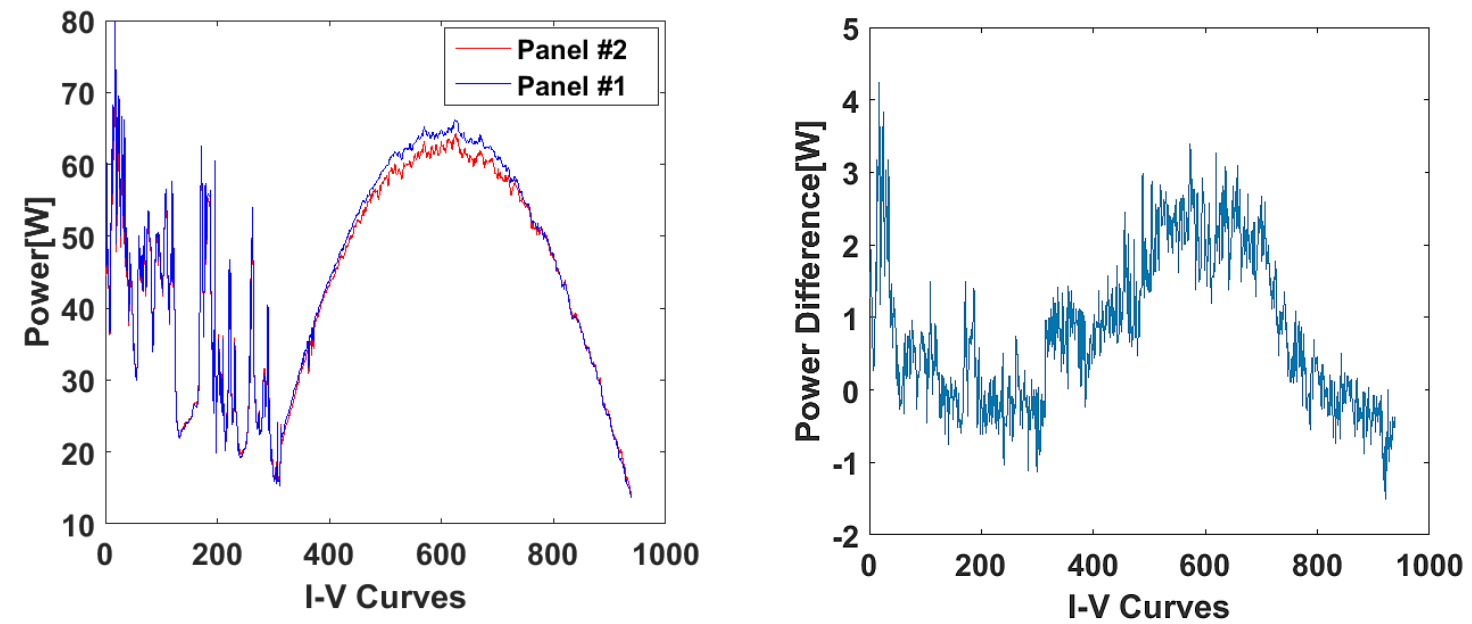

Fig. 18. Powers and power difference.

Furthermore, the voltage and the voltage difference are shown on the left and right side of Fig. 19, respectively. The estimated voltage difference is almost less than $1 \%$, which is acceptable as two identical PV modules have been used; however, it reaches $1.5 \%$ in a few points.
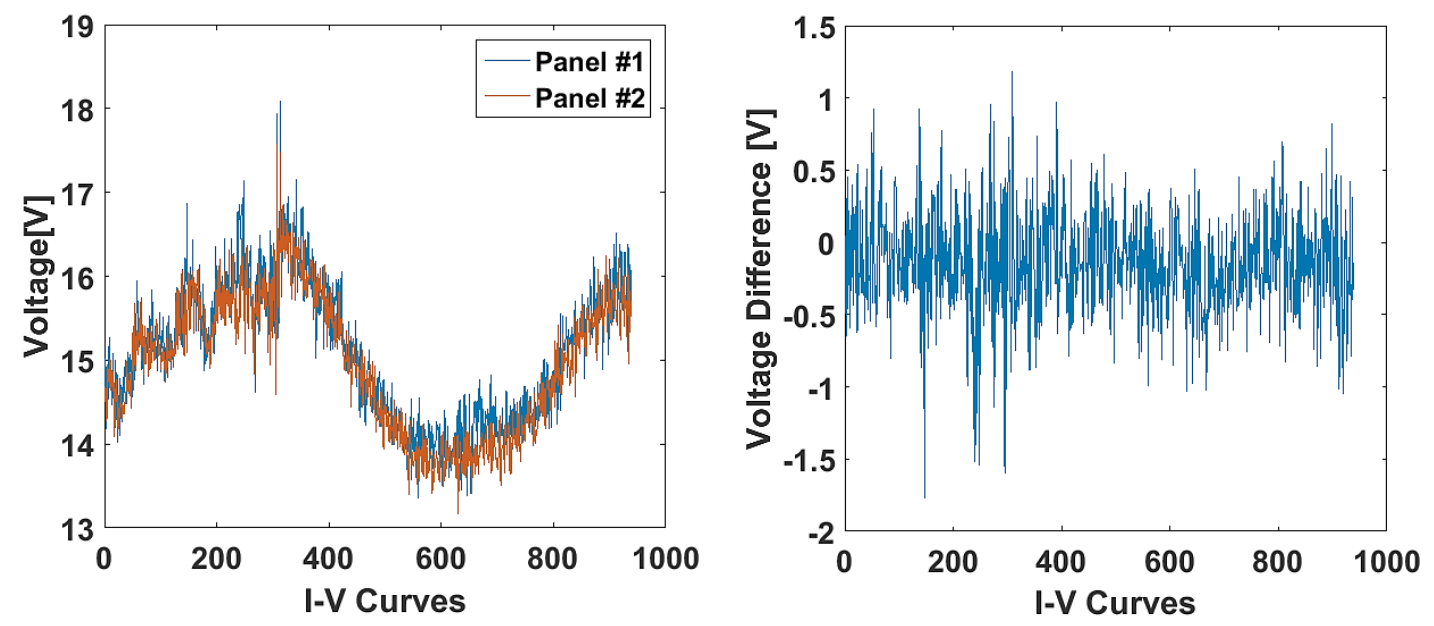

Fig. 19. Voltages (left) and voltages difference (right).

It can be concluded from the Fig. 18 that Module \#1 can produce more power in higher irradiations. As the measurements were taken once every 30 seconds, the total amount of power is then multiplied by 30 seconds to calculate the generated energy. Table V shows the total energy generated by both PV modules and the difference between them. As can be seen, Module \#1 generated $23 \mathrm{~kJ}$ more energy than Module \#2 and the percentage difference is $1.8 \%$. The energy difference is calculated regarding the first module as the reference.

Table V. Generated Energy by PV modules.

\begin{tabular}{cc}
\hline & Energy \\
\hline Module \#1 & $1262.5 \mathrm{~kJ}$ \\
\hline Module \#2 & $1239.5 \mathrm{~kJ}$ \\
\hline Difference & $23 \mathrm{~kJ}$ \\
\hline \% Difference & $1.8 \%$ \\
\hline
\end{tabular}

According to the Eq.6, MB algorithm needs three parameters ( $\mathrm{A} 0$ to $\mathrm{A} 3$ ) to operate and estimate the $\mathrm{V}_{\mathrm{mp}}$. The same procedure 
in Section IV has been conducted to calculate these parameters. Each PV module creates different algorithm parameters for the MB algorithm. The parameters are calculated and summarized in Table VI for two identical $80 \mathrm{~W}$ PV modules. Because the PV modules are identical, the MB parameters are somehow in a close range; however, they are not identical. Table VI summarizes the MB parameters for each PV module.

Table VI. MB algorithm parameters for Modules.

\begin{tabular}{ccccc}
\hline & A0 & A1 & A2 & A3 \\
\hline Module \#1 & $38.1181 \mathrm{~V}$ & $-0.0715 \mathrm{~V} / \mathrm{K}$ & 0.2611 & -0.5061 \\
\hline Module \#2 & $41.0837 \mathrm{~V}$ & $-0.0818 \mathrm{~V} / \mathrm{K}$ & 0.4319 & -0.4867 \\
\hline
\end{tabular}

\section{B. REAL-TIME IDENTICAL PV MOdULES PERFORMANCE COMPARISON}

This section dedicates to the comparison of identical PV modules in real-time. To complete the performance evaluation of the identical PV modules in real-time, the MB algorithm with the parameters calculated in section A and reported in Table VI are used. PV modules were tested during a day with variable environmental conditions, as shown in Fig. 20. As can be seen, the duration of the test is approximately 7 hours, and the data are captured in real-time with switching frequency equal to $20 \mathrm{kHz}$ and the algorithm frequency equal to $30 \mathrm{~Hz}$. The temperature varies from $308 \mathrm{~K}$ to $321 \mathrm{~K}$, and the solar irradiation reaches more than $1000 \mathrm{~W} / \mathrm{m} 2$ at some points.
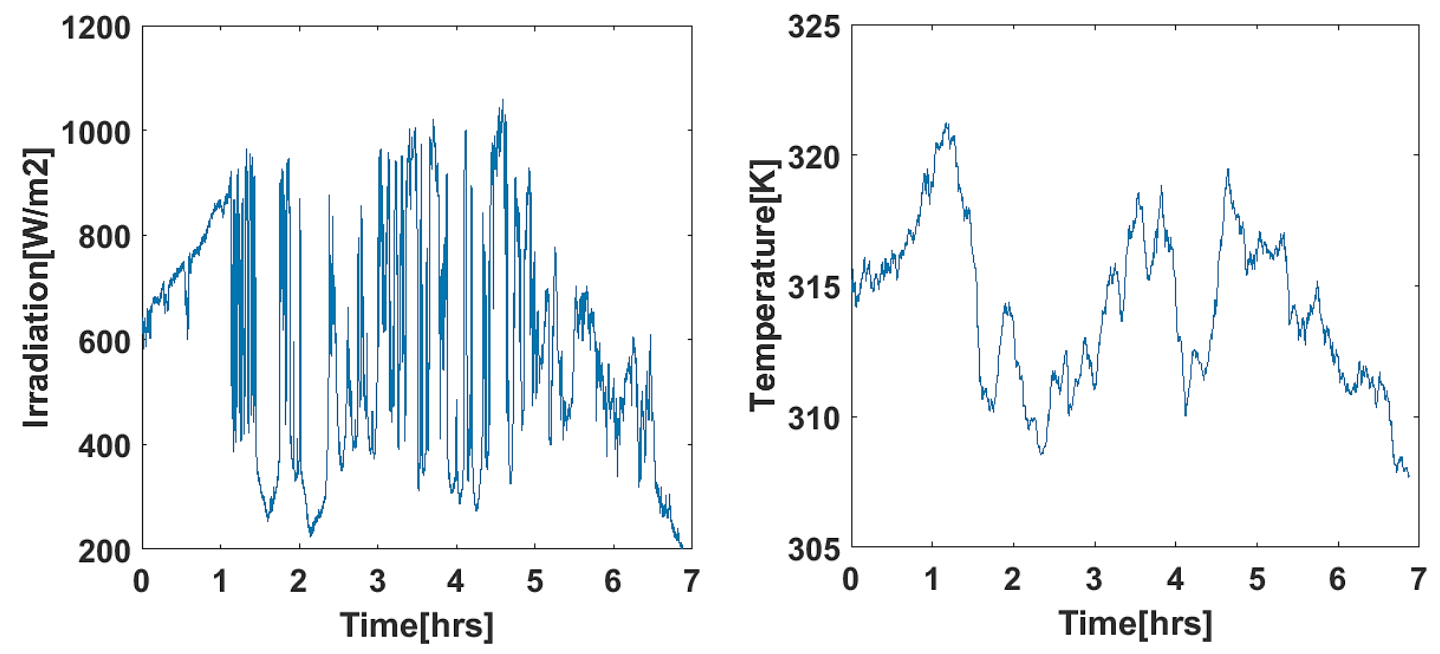

Fig. 20. Solar irradiation and module temperature.

The voltages and powers of both PV modules have been captured and depicted on the right and the left side of Fig. 21, respectively.
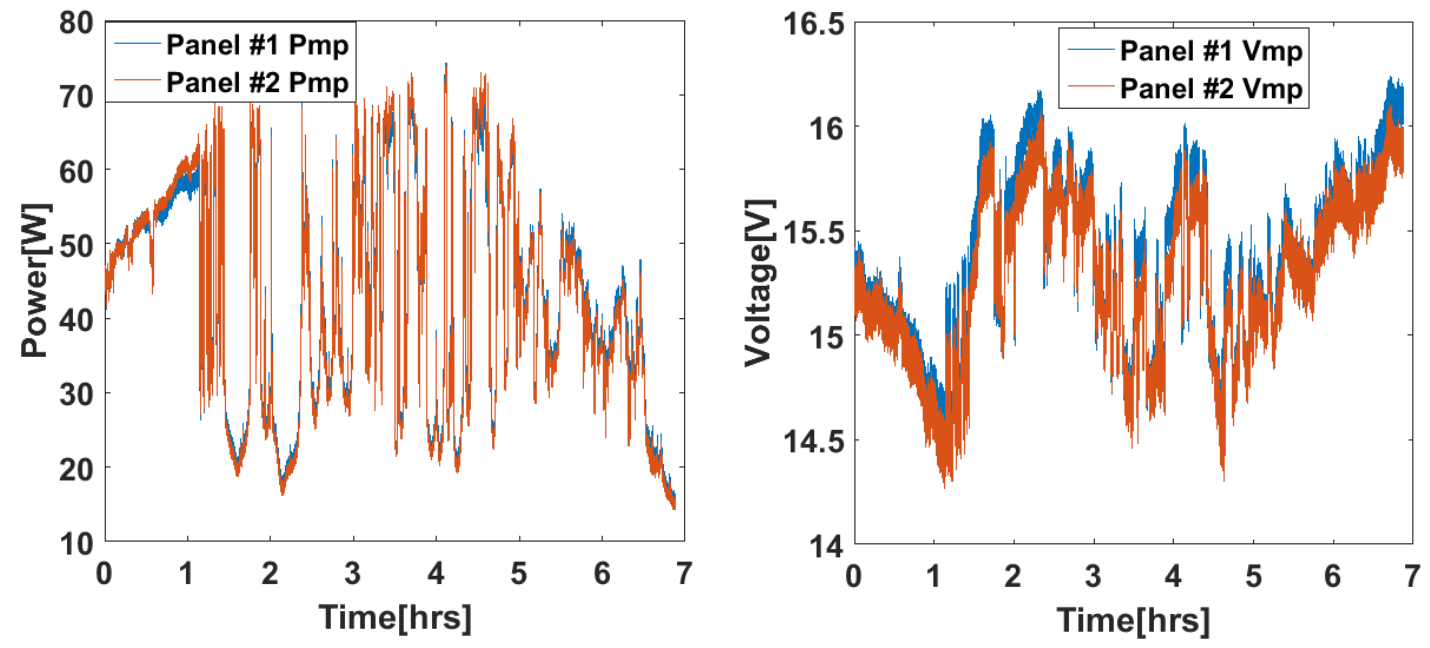

Fig. 21. Generated powers (left) and voltages (right). 
As shown in Fig. 21, the power varies in the interval between $15 \mathrm{~W}$ and $75 \mathrm{~W}$. As it was expected, Module \#1 can produce more power and thus the energy in higher irradiations. However, the $\mathrm{V}_{\mathrm{mp}}$ of Module \#1 is higher than the other modules in almost all cases.

Table VII summarizes the generated energy, difference and percentage difference between two modules in real-time. The percentage difference in the energy generated by both modules is approximately $0.6 \%$. It must be mentioned that the difference is calculated with respect to Module \#1.

Table VII Energy generated by the PV modules and the related difference.

\begin{tabular}{ccccc}
\hline & Module \#1 & Module \#2 & difference & \%difference \\
\hline Energy & $1039.4 \mathrm{~kJ}$ & $1032.9 \mathrm{~kJ}$ & $6.5 \mathrm{~kJ}$ & $0.6 \%$ \\
\hline
\end{tabular}

To clarify the performance of the PV modules, the difference between the voltages and powers of both modules are measured and depicted in Fig. 22. As shown, the estimated voltages by the MB algorithm for both PV modules are approximately the same as the voltage difference is maximum $0.4 \mathrm{~V}$. However, the power difference reaches up to $6 \mathrm{~W}$ as the current changes by changing the estimated voltage at MPP, thus making such a difference in the powers.
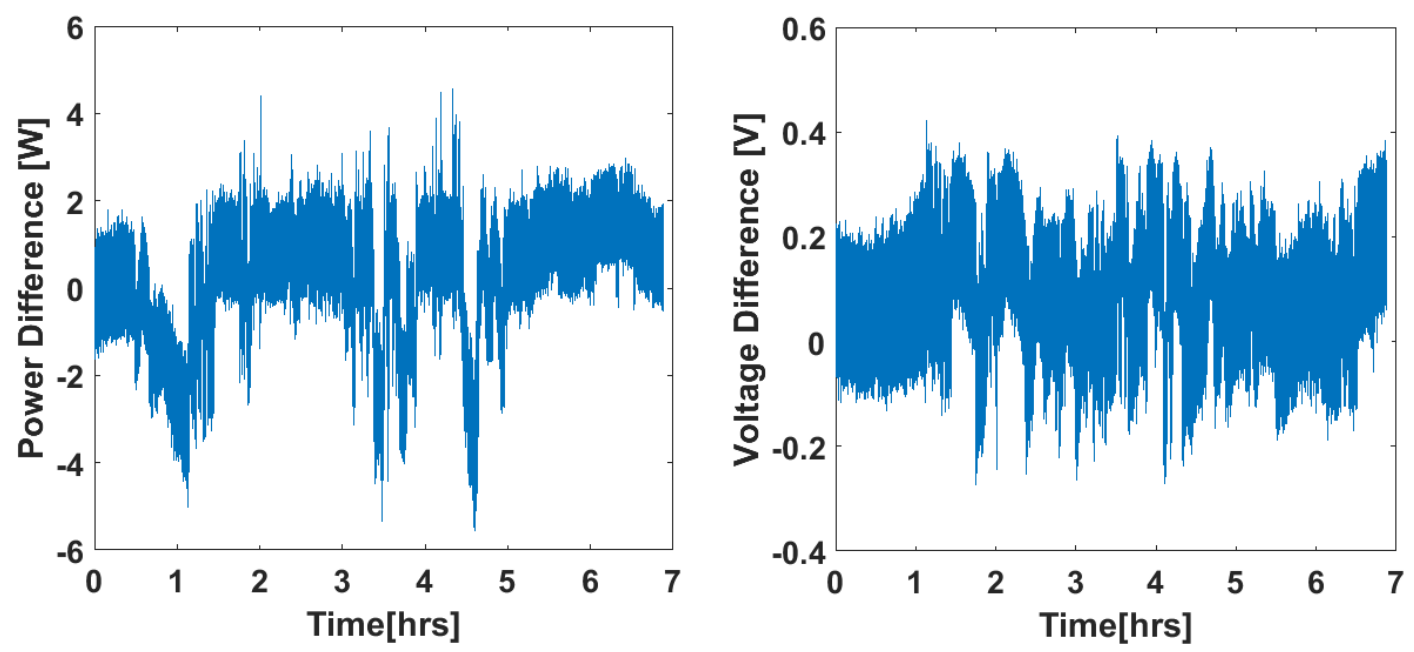

Fig. 22. Power difference (left) and voltage difference (right).

\section{CONCLUSION}

This paper presents the design and development of an experimental testing system, which is capable of reproducing environmental conditions for comparing and characterizing two photovoltaic modules in real-time and evaluating MPPT algorithms. Some constraints such as ease of use and flexibility have been considered during the design phase. As shown in the paper, two identical PV modules have been used to compare their performances in energy generation point of view. The tests have been conducted using the same model-based MPPT algorithm, showing that both PV modules cannot produce the same amount of energy at the same environmental condition. PV Module \#1 could produce 1.8\% more energy than the PV module \#2. In addition, the real-time energy generation comparison has been conducted, and it has been reported that Module \#1 can produce $0.6 \%$ more energy than Module \#2. The results show that the developed experimental test rig is a flexible and low-cost system, which aims to easily embed and simulate MPPT algorithms and compare the performance of many MPPT algorithms and PV modules, simultaneously.

\section{REFERENCES}

[1] D. S. Codd, A. Carlson, J. Rees, A. H. Slocum A low cost high flux solar simulator Solar Energy 84(2010) pp.2202-2212.

[2] L. Cristaldi, M. Khalil, P. Soulatiantork, "A root cause analysis and a risk evaluation of PV balance of systems failures", The International Measurement Confederation Journal (IMEKO), Vol. 6, No.4, pp. 113-120, Dec 2017. DOI: http://dx.doi.org/10.21014/acta_imeko.v6i4.425.

[3] Cristaldi, M. Khalil, M. Faifer, P. Soulatiantork, "Markov process reliability model for photovoltaic module encapsulation failures", 4th international conference on renewable energy research and applications, Palermo, Italy, pp. 22-25 Nov 2015. DOI: 10.1109/ICRERA.2015.7418696.

[4] T. Esram and P. L. Chapman, "Comparison of photovoltaic array maximum power point tracking techniques", IEEE Transactions on Energy Conversion, vol. 22, no. 2, June 2007, pp. 439-449.

[5] Soulatiantork - P 2016, 'Experimental performance evaliation of MPPT algorithms for photovoltaic systems', P.h.D theses, Politecnico di Milano, Milano, Italy.

[6] M. A. G. de Brito, L. Galotto, L. P. Sampaio, G. A. Melo and C. A. Canesin "Evaluation of the Main MPPT Techniques for Photovoltaic Applications", IEEE Transactions on Industrial Electronics, vol. 60, no. 3, May 2012, pp. 1156-1167. 
[7] T. Y. Sea, J. S. Ka, C. U. Lee and D. H. Chung, "MPPT performance improvement of PV system using Hybrid-PI controller”, 13th ICCAS October 2013, pp. $434-436$.

[8] J. R. Vazquez, A. D. Martin and R. S. Herrera, "Neuro-Fuzzy control of a grid-connected photovoltaic system with power quality improvement", IEEE EUROCON 2013, July 2013, pp. $850-856$.

[9] U.R. Yaragatti, A. N. Rajkiran, B. C. Shreesha, "A novel method of fuzzy controlled maximum power point tracking in photovoltaic systems", IEEE ICIT, Dec. 2005, pp. 1421-1426.

[10] Elamim, Abderrazzak \& Hartiti, Bouchaib \& Haibaoui, Amine \& Abderrazak, Lfakir \& Thevenin, Philippe. (2017). Analysis and comparison of different PV technologies for determining the optimal PV panels- A case study in Mohammedia , Morocco.. IOSR Journal of Electrical and Electronics Engineering (IOSR-JEEE). 12. 37-45. 10.9790/1676-1201013745.

[11] A.J Carr, T.L Pryor, A comparison of the performance of different PV module types in temperate climates, Solar Energy, Volume 76, Issues 1-3, 2004, Pages 285-294, ISSN 0038-092X, https://doi.org/10.1016/j.solener.2003.07.026.

[12] Fan Jiang and A. Wong, "Study on the performance of different types of PV modules in Singapore," 2005 International Power Engineering Conference, Singapore, 2005, pp. 1-109.

[13] N. M. A. Alrahim Shannan, N. Z. Yahaya and B. Singh, "Single-diode model and two-diode model of PV modules: A comparison," 2013 IEEE International Conference on Control System, Computing and Engineering, Mindeb, 2013, pp. 210-214.

[14]Ahmad H. Besheer, Ahmed M. Kassem \& Almoataz Y. Abdelaziz (2014) Single-diode Model Based Photovoltaic Module: Analysis and Comparison Approach, Electric Power Components and Systems, 42:12, 1289-1300.

[15] Xianwen Gao, Shaowu Li, Rongfen Gong, "Maximum power point tracking control strategies with variable weather parameters for photovoltaic generation systems", Solar Energy, Volume 93, 2013, pp 357-367, ISSN 0038-092X, https://doi.org/10.1016/j.solener.2013.04.023.

[16] Po-Cheng Chen, Po-Yen Chen, Yi-Hua Liu, Jing-Hsiao Chen, Yi-Feng Luo, "A comparative study on maximum power point tracking techniques for photovoltaic generation systems operating under fast changing environments", Solar Energy, Volume 119, 2015, pp. 261-276, ISSN 0038-092X.

[17] Shaowu Li, A variable-weather-parameter optimization strategy to optimize the maximum power point tracking speed of photovoltaic system, Solar Energy, Volume 113, 2015, pp 1-13, ISSN 0038-092X, https://doi.org/10.1016/j.solener.2014.12.023.

[18] E.E. van Dyk, A.R. Gxasheka, E.L. Meyer, "Monitoring current-voltage characteristics and energy output of silicon photovoltaic modules", Renewable Energy, Volume 30, Issue 3, March 2005, Pages 399-411,

[19] J. Munoz, E. Lorenzo, "Capacitive load based on IGBTs for on-site characterization of PV arrays ", Solar Energy, 80, 2006, pp. 1489-1497.

[20] Al Ameri, O. A.and Serhan, M. A.and Lamont, L. A.and El Chaar, L. "Variable Electronic Load for Testing PV Performance1" Applied Solar Energy,2010, Vol.46, pp. 89-96.

[21] Y. Kuai, S. Yuvarajan, "An electronic load for testing photovoltaic modules", Journal of Power Sources, 154, 2006, pp. 308-313.

[22] J.M. Enrique, E. Duran, M. Sidrach-de-Cardona, J.M. Andujar, M.A. Boh6rquez, J.E. Carretero, "A new approach to obtain I-V and P-V curves of PV modules by using DC-DC converters", 31st IEEE PVSC, 2005, pp. 1769-1772.

[23] N. Lima Nelio, C.de Freitas, M.Gustavo, "Low Complexity System for Real-Time Determination of Current-Voltage Characteristic of PV modules and strings" Applied Power Electronics Conference and Exposition (APEC), 28th Annual IEEE, 17-21 March 2013 pp.2817-2823.

[24] E. Duran, J. Galan, M. Sidrach-de-Cardona, and J. M. Andujar, "A New Application of the Buck-Boost-Derived Converters to Obtain the I-V Curve of Photovoltaic Modules," 2007 IEEE Power Electronics Specialists Conference, Orlando, FL, 2007, pp. 413-417.

[25] P. Solatian, S. Hamidreza Abbasi, and F. Shabaninia, "Simulation Study of Flow Control Based on PID ANFIS Controller for NonLinear Process Plants," Am. J. Intell. Syst., vol. 2, no. 5, pp. 104-110, 2012. DOI: 10.5923/j.ajis.20120205.04.

[26] Payam Soulatiantork, Alireza Alghassi, Marco Faifer, Suresh Perinpanayagam, IGBT Thermal Stress Reduction Using Advance Control Strategy, Procedia CIRP, Volume 59, 2017, Pages 274-279. https://doi.org/10.1016/j.procir.2016.09.040.

[27] Adam-4000 series Data Acquisition Modules User's Manual.

[28] Alireza Alghassi, Payam Soulatiantork, Mohammad Samie, Adrian Uriondo Del Pozo, Suresh Perinpanayagam, Marco Faifer, Fault Tolerance Enhance DCDC Converter Lifetime Extension, Procedia CIRP, Volume 59, 2017, pp 268-273. https://doi.org/10.1016/j.procir.2017.02.014.

[29] M. Faifer, L. Cristaldi, L. Piegari, and P. Soulatiantork, "Design of a converter for photovoltaic modules testing," Clean Electrical Power (ICCEP), 2015 International Conference on, Taormina, 2015, pp. 674-681. DOI: 10.1109/ICCEP.2015.7177564.

[30] M. Faifer, M. Khalil, L. Piegari, P. Soulatiantork, S. Toscani, " Improvement in the efficiency of DC-DC power converters by controlling the switching frequency," in proceeding of IMEKO TC10 Workshop on Technical Diagnostics, Advanced measurement tools in technical diagnostics for, systems' reliability and safety, Milan, Italy, June 2016.

[31] L. Cristaldi, M. Faifer, M. Rossi, and S. Toscani, "A simplified model of a photovoltaic module," in Proc. Int. Instrum. Meas. Technol. Conf., May 2012, pp. 431-436.

[32] L. Cristaldi, M. Faifer, M. Rossi and S. Toscani, "An Improved Model-Based Maximum Power Point Tracker for Photovoltaic Modules," in IEEE Transactions on Instrumentation and Measurement, vol. 63, no. 1, pp. 63-71, Jan. 2014.

[33] M. Faifer, L. Cristaldi, S. Toscani, P. Soulantiantork and M. Rossi, "Iterative model-based Maximum Power Point Tracker for photovoltaic modules," 2015 IEEE International Instrumentation and Measurement Technology Conference (I2MTC) Proceedings, Pisa, 2015, pp. $1273-1278$. DOI: $10.1109 /$ I2MTC.2015.7151456.

[34] L. Cristaldi, M. Faifer, M. Rossi, S. Toscani. "A New Approach to Maximum Power Point Tracking for Photovoltaic Modules, " in Proc. IEEE Int. Conf. on Clean Electrical Power, Alghero, Italy, June 11-13, 2013, pp.461-465. 